\title{
Raman spectroscopy: A rapid method to assess the effects of pasture feeding on the nutritional quality of butter
}

\author{
L. G. Gómez-Mascaraque, ${ }^{1,2 *}$ K. Kilcawley, ${ }^{3}$ D. Hennessy, ${ }^{2,4}$ J. T. Tobin, ${ }^{1,2}$ and T. F. O’Callaghan ${ }^{1,2}$ \\ ${ }^{1}$ Food Chemistry and Technology Department, Teagasc Moorepark Food Research Centre, Fermoy, Co. Cork, P61 C996, Ireland \\ ${ }^{2}$ VistaMilk SFI Research Centre, Teagasc, Moorepark, Fermoy, Co. Cork, P61 P302, Ireland \\ ${ }^{3}$ Food Quality and Sensory Science Department, Teagasc Moorepark Food Research Centre, Fermoy, Co. Cork, P61 C996, Ireland \\ ${ }^{4}$ Teagasc, Animal and Grassland Research and Innovation Centre, Moorepark, Fermoy, Co. Cork, P61 P302, Ireland
}

\begin{abstract}
The animal diet is a critical variable affecting the composition and functionality of dairy products. As "Grass-Fed" labeling becomes more prominent on the market, rapid and label-free methods for verification of feeding systems are required. This work proposes the use of Raman spectroscopy to study the effects of 3 different experimental cow feeding systems - perennial ryegrass pasture, perennial ryegrass with white clover pasture, and an indoor total mixed ration diet (TMR) on the nutritional quality of sweet cream butter. The results demonstrate that Raman spectroscopy coupled with multivariate analysis is a promising approach to distinguish butter derived from pasture or conventional TMR feeding systems. A Pearson correlation analysis confirmed high positive correlations between the spectral bin at $1,657 \mathrm{~cm}^{-1}$, ascribed to the stretching vibrations of $\mathrm{C}=\mathrm{C}$ bonds, and concentrations of $\alpha$-linolenic acid and conjugated linolenic acid (CLA) in butter, and in general with the concentration of n-3 and n$3+$ CLA fatty acids and polyunsaturated fatty acids in the samples. The yellow color indicative of the presence of carotenoids in butter, which has previously been suggested as a biomarker of pasture or "Grass-Fed" feeding, was also positively correlated with the data obtained from the Raman spectra. Raman spectroscopy could also be used to accurately predict indicators of the nutritional quality of butter, such as the thrombogenic index, which showed a strong negative correlation with the spectral bin at $3,023 \mathrm{~cm}^{-1}$.
\end{abstract}

Key words: Raman, grass-fed, TMR, animal diet

\section{INTRODUCTION}

Multiple environmental-, cow-, and farm-level factors can influence the composition and quality of bovine

Received April 15, 2020.

Accepted May 30, 2020.

*Corresponding author: Laura.Mascaraque@teagasc.ie milk and dairy products thereof, including animal genetics, age, stage of lactation, health status, and diet (Alothman et al., 2019). In particular, animal diet has been identified as an effective means of tailoring nutritional characteristics of bovine milk (Dewhurst et al., 2006). The composition of the lipid fraction of milk, in particular, is affected by the cow feeding system (Chilliard et al., 2007). For instance, it has a significant effect on the level of SFA and UFA in milk (Chilliard et al., 2001). Pasture-based diets, such as those broadly practiced in Ireland and New Zealand, are reported to result in a higher fat content in milk, with higher concentrations of beneficial nutrients such as PUFA, CLA, and a more nutritionally desirable ratio of n- 6 to $n-3$ fatty acids than TMR diets (White et al., 2001; Couvreur et al., 2006; O'Callaghan et al., 2016b). These compositional differences in milk, which are translated into its derived products such as cheese (Revello Chion et al., 2010; O'Callaghan et al., 2017) or butter (Mallia et al., 2008; O'Callaghan et al., 2016a), affect not only the nutritional quality of dairy products but also their sensorial attributes and functional properties (Hurtaud et al., 2007; Hurtaud and Peyraud, 2007; Faulkner et al., 2018; Magan et al., 2019).

As "Grass-Fed" labeling becomes more prominent as a product differentiator within the market, methods for verification of feeding systems are needed. Several tools for quantitative compositional analysis, coupled with multivariate data analyses, have been proposed to investigate the influence of diet on milk and butter quality. Fatty acid profiling has been suggested as a potential method for identification of the feeding system used during milk production (Alothman et al., 2019). Capuano et al. (2014) reported that fatty acid profiling combined with chemometrics is an effective approach to verify whether milk has been obtained from pasturebased feeding systems. More recently, O'Callaghan et al. $(2016 \mathrm{a}, \mathrm{b})$ confirmed the ability of fatty acid profiling combined with multivariate analysis to discriminate milk and butter samples according to the cow feeding systems from which they were derived. However, 
fatty acid profiling generally involves multiple steps, including lipid extraction and derivatization before analysis by gas chromatography, so it is considerably time and labor intensive. O'Callaghan et al. (2018) also demonstrated the ability of proton nuclear magnetic resonance to distinguish between pasture-derived and non-pasture-derived milks. Nevertheless, research efforts are still needed to develop rapid, label-free tools to assess the quality of milk and dairy products that could be used more conveniently for milk processors and manufacturers. This would allow them to quantitatively exploit the uniqueness of their production system, especially for grass-based dairy, which is rather unique from a global perspective.

However, the nutritional quality of the lipid fraction of milk does not depend exclusively on its fatty acid profile but is also affected by the presence of micronutrients, whose abundance also depend on the cow feeding system (Alothman et al., 2019). For instance, higher levels of bioactive compounds such as $\beta$-carotene, vitamins, or terpenes have been reported for pasture-derived milk compared with TMR-derived milk (Agabriel et al., 2007; O'Callaghan et al., 2016a, 2017), which can also have significant effects on product color and region-specific consumer acceptance.

Through analysis of the inelastic scattering of light, Raman spectroscopy allows detection and quantification of compounds in complex samples with minimal sample preparation, in a nondestructive, noninvasive, and label-free manner (Butler et al., 2016), even at trace levels (Liu et al., 2013; Peng et al., 2017). Among food components, Raman spectroscopy is particularly useful for studying lipids and lipophilic micronutrients, because nonpolar groups yield strong Raman bands (Baeten et al., 1998; Baeten, 2010). Moreover, Raman spectroscopy is especially sensitive to the level of unsaturation in fats, because the Raman bands ascribed to the stretching vibration of ethylene groups are considerably intense, whereas the corresponding bands in infrared spectra are very weak (van de Voort et al., 2001). Hence, Raman spectroscopy has been successfully used to determine the unsaturation level in edible fats (Olsen et al., 2007), including milk fat (El-Abassy et al., 2012), and to predict the fatty acid composition in clarified butter and vegetable oils (Beattie et al., 2004a; Dong et al., 2013). The efficiency of Raman spectroscopy for the analysis of micronutrients such as carotenoids in foods has also been demonstrated (Hara et al., 2018; Portarena et al., 2019).

The aim of the present pilot study was to assess the potential of Raman spectroscopy to detect changes in the composition and subsequent quality of butter related to differences in cow feeding systems, as a rapid and label-free alternative to the existing laborious analytical approaches. For this purpose, sweet cream butter was produced at pilot scale from milk obtained from cows fed on 3 experimental dietary treatments: perennial ryegrass pasture (GRS), perennial ryegrass with white clover pasture (CLV), and an indoor TMR. The butter samples were analyzed in terms of fatty acid composition and color (related to the presence of carotenoids; Nozière et al., 2006), and the results were correlated with the differences observed in their Raman spectra.

\section{MATERIALS AND METHODS}

\section{Reagents}

Heptane, sodium hydrogen monohydrate, and 25\% sodium methoxide were purchased from Sigma-Aldrich (Dublin, Ireland). Diethyl ether was purchased from Fisher Scientific (Dublin, Ireland). The internal standard trinonadecanoin (C19:0; part number T-165) and a standard of CLA were purchased from Nu-Chek Prep Inc. (Elysian, MN). Fatty acid methyl ester standard mix containing C4:0 to C24:0 (part number 35077) was purchased from Thames Restek UK Ltd. (High Wycombe, UK).

\section{Experimental Design and Milk Collection}

Three experimental dietary treatments were established at Teagasc, Animal and Grassland Research and Innovation Centre, Moorepark, Fermoy, Co. Cork, Ireland, as previously described by O'Callaghan et al., (2016a,b, 2017). Briefly, 54 spring-calving Friesian cows were allocated to 3 groups ( $\mathrm{n}=18$ per group). Three feeding systems were compared over a full lactation: herd 1 was housed indoors and fed a TMR, herd 2 was maintained outdoors on perennial ryegrass-only pasture (GRS), and herd 3 was also maintained outdoors on a perennial ryegrass and white clover pasture (CLV). To obtain representative samples of milk, the herds of each of the 3 feeding systems were milked separately into designated 5,000-L refrigerated tanks. Approximately $1,000 \mathrm{~kg}$ of each discrete milk sample, encompassing 2 sequential morning and evening milkings, were collected for subsequent butter manufacture. The evening milk was stored at $4^{\circ} \mathrm{C}$ overnight, to which the morning milk was then added and agitated before collection. Bulk milk samples $(\sim 1,000 \mathrm{~L})$ were collected after the morning milking.

\section{Production of Butter}

Butter was produced using the Moorepark Technology Ltd. pilot-plant facilities (Teagasc Food Research 
Centre, Moorepark, Fermoy, Co. Cork, Ireland) following the method described by O'Callaghan et al. (2016a). Briefly, approximately 1,000 L of milk from each of the diets were pasteurized at $77^{\circ} \mathrm{C}$ for $15 \mathrm{~s}$ using a semi-commercial pasteurizer (Unison Engineering Ltd., Limerick, Ireland), cooled to $50^{\circ} \mathrm{C}$, and skimmed using a cream separator (Westfalia separator d-4740, GEA, Naas, Ireland) producing a cream containing 38 to $40 \%$ fat content. Approximately $50 \mathrm{~L}$ of cream was then stored overnight at $5^{\circ} \mathrm{C}$ to allow fat crystallization. Butter manufacture was carried out using a butter churn with a cream capacity of 50 L (ASTA Eismann GmbH, Neubeckum, Germany). Cream was churned, and the buttermilk was drained, after which the butter grains were rinsed 3 times with cold reverse osmosis water. The butter was kneaded and salted to a $1.8 \%$ salt content using a $50 \%$ salt slurry mix (wt/vol), and the butter was subsequently worked and packed off in cylindrical tubes and wrapped in a layer of grease-proof paper and covered in aluminum foil.

\section{Fatty Acid Analysis}

Fatty acid analysis was performed according to the method described by O'Callaghan et al. (2016a, 2020).

\section{Color Analysis}

Color measurements were taken from the surface of the butter samples as previously described by O'Callaghan et al. (2016a), using a Minolta Chroma-Meter CR-400 (Mason Technology Ltd., Dublin, Ireland). Each sample was measured 5 times, and the average of each sample was recorded.

\section{Raman Spectroscopy}

Internal sections of the butter samples, cut with a blade, were placed on glass microscopy slides and equilibrated at $20^{\circ} \mathrm{C}$ before analysis using a Linkam PE94 heating/cooling microscopy stage (Linkam Scientific Instruments Ltd., Tadworth, UK). An Alpha300 R confocal Raman microscope (WITec GmbH, Ulm, Germany), equipped with a 532-nm laser and an ultra-fast Raman imaging charge-coupled device (CCD) camera, was used to collect 5 different Raman spectra of each sample at different randomly selected positions. A $50 \times$ microscope objective (0.55 numerical aperture) was used, the laser power was set at $20 \mathrm{~mW}$, the integration time at $0.5 \mathrm{~s}$, and the number of accumulations at 10. Project Five software version 5.0 (WITec) was used to process the raw spectra. A cosmic ray removal correction function (filter size 3, dynamic factor 8) and a shape function for the background subtraction (shape size 250 , noise factor 1 ) were applied to each individual spectrum. The 5 processed spectra of each sample were then averaged.

\section{Statistical Analysis}

To perform univariate statistical analysis of the data, IBM SPSS Statistics software was used (v. 24; IBM Corp., Armonk, NY). Shapiro-Wilk and Levene's tests were performed to assess normality of the data and homogeneity of variances, respectively. The statistical significance of the differences observed between samples was assessed through one-way ANOVA, using the Tukey post-hoc test for multiple comparisons when the variances could be assumed homogeneous and the Dunnett T3 correction when an assumption of homogeneity could not be made. The significance level was fixed at $\alpha=0.05$ for all tests.

MetaboAnalyst online software (v. 4.0, www .metaboanalyst.ca; Chong et al., 2019) was used to perform chemometrics analysis: principal component analysis (PCA), partial least squares discriminant analysis (PLS-DA), and cluster analysis (heatmaps). Range scaling was applied to the data before performing the multivariate analyses, to compare all variables relative to their response ranges. Correlation analyses were also performed using MetaboAnalyst software.

\section{RESULTS AND DISCUSSION}

\section{Fatty Acid Composition}

A total of 28 fatty acids (FA) were quantified from each butter sample, 19 of which varied significantly $(P \leq 0.05)$ between the different diets. The results are shown in Table 1, together with some functionality and nutritional indices calculated thereof. Arguably, the FA composition of butter was significantly affected by the cow feeding system. Milk fat derived from pasture feeding contains higher quantities of beneficial FA than that of TMR-derived milk fat (Alothman et al., 2019). Indeed, TMR butter in this study had a significantly higher content of SFA and a significantly lower content of PUFA than both pasture-based feeding systems, as previously reported for milk fat (White et al., 2001; Kučević et al., 2016) and, in particular, for butter (Couvreur et al., 2006; O'Callaghan et al., 2016a). A significantly higher ratio of n-3 to n-6 was observed for butter derived from pasture feeding, as previously described for milk fat (Benbrook et al., 2018). Also, GRS and CLV butter samples exhibited significantly lower atherogenicity and thrombogenic indices, both calculated according to Ulbricht and Southgate (1991). The TMR butter, on the other hand, had higher 
Table 1. Fatty acid triglyceride content (grams per $100 \mathrm{~g}$ of butter fat) and CIE color coordinates (L*a*b*) of butter from different cow feeding systems; values are expressed as average $\pm \mathrm{SD}$

\begin{tabular}{|c|c|c|c|c|}
\hline \multirow[b]{2}{*}{ Variable } & \multicolumn{3}{|c|}{ Feeding system ${ }^{1}$} & \multirow[b]{2}{*}{$P$-value } \\
\hline & GRS & CLV & TMR & \\
\hline Butyric acid (C4:0) & $5.82 \pm 0.19^{\mathrm{a}}$ & $5.35 \pm 0.32^{\mathrm{b}}$ & $5.33 \pm 0.30^{\mathrm{b}}$ & 0.011 \\
\hline Caproic acid (C6:0) & $3.10 \pm 0.08^{\mathrm{a}}$ & $2.90 \pm 0.19^{\mathrm{ab}}$ & $2.87 \pm 0.11^{\mathrm{b}}$ & 0.023 \\
\hline Caprylic acid (C8:0) & $1.84 \pm 0.05^{\mathrm{a}}$ & $1.73 \pm 0.17^{\mathrm{ab}}$ & $1.69 \pm 0.06^{\mathrm{b}}$ & 0.063 \\
\hline Capric acid (C10:0) & $4.36 \pm 0.17^{\mathrm{a}}$ & $4.15 \pm 0.55^{\mathrm{a}}$ & $4.11 \pm 0.15^{\mathrm{a}}$ & 0.438 \\
\hline Undecanoic acid (C11:0) & $0.17 \pm 0.02^{\mathrm{a}}$ & $0.24 \pm 0.09^{\mathrm{ab}}$ & $0.12 \pm 0.01^{\mathrm{b}}$ & 0.006 \\
\hline Lauric acid (C12:0) & $4.88 \pm 0.19^{\mathrm{a}}$ & $4.87 \pm 0.68^{\mathrm{a}}$ & $4.84 \pm 0.16^{\mathrm{a}}$ & 0.985 \\
\hline Tridecanoic acid (C13:0) & $0.18 \pm 0.02^{\mathrm{a}}$ & $0.18 \pm 0.05^{\mathrm{ab}}$ & $0.13 \pm 0.01^{\mathrm{b}}$ & 0.034 \\
\hline Myristic acid (C14:0) & $12.98 \pm 0.15^{\mathrm{a}}$ & $13.17 \pm 0.74^{\mathrm{ab}}$ & $13.31 \pm 0.20^{\mathrm{b}}$ & 0.474 \\
\hline Myristoleic acid (C14:1) & $0.95 \pm 0.07^{\mathrm{a}}$ & $1.10 \pm 0.08^{\mathrm{b}}$ & $0.95 \pm 0.04^{\mathrm{a}}$ & 0.001 \\
\hline Pentadecanoic acid (C15:0) & $1.48 \pm 0.09^{\mathrm{a}}$ & $1.62 \pm 0.12^{\mathrm{a}}$ & $1.25 \pm 0.03^{\mathrm{b}}$ & $<0.0005$ \\
\hline Palmitic acid (C16:0) & $30.62 \pm 1.05^{\mathrm{a}}$ & $30.07 \pm 0.70^{\mathrm{a}}$ & $35.29 \pm 0.94^{\mathrm{b}}$ & $<0.0005$ \\
\hline Palmitoleic acid (C16:1) & $1.59 \pm 0.14^{\mathrm{a}}$ & $1.49 \pm 0.18^{\mathrm{a}}$ & $1.43 \pm 0.02^{\mathrm{a}}$ & 0.127 \\
\hline Heptadecanoic acid (C17:0) & $0.65 \pm 0.02^{\mathrm{a}}$ & $0.64 \pm 0.02^{\mathrm{a}}$ & $0.57 \pm 0.01^{\mathrm{b}}$ & $<0.0005$ \\
\hline Stearic acid $(\mathrm{C} 18: 0)$ & $9.88 \pm 0.65^{\mathrm{a}}$ & $9.77 \pm 0.45^{\mathrm{a}}$ & $9.45 \pm 0.42^{\mathrm{a}}$ & 0.353 \\
\hline Oleic acid $(\mathrm{C} 18: 1 \mathrm{n}-9 \mathrm{cis})$ & $17.01 \pm 0.34^{\mathrm{a}}$ & $17.51 \pm 1.89^{\mathrm{ab}}$ & $15.28 \pm 0.92^{\mathrm{b}}$ & 0.017 \\
\hline Elaidic acid (C18:1n-9 trans) & $0.34 \pm 0.08^{\mathrm{a}}$ & $0.32 \pm 0.08^{\mathrm{a}}$ & $0.25 \pm 0.11^{\mathrm{a}}$ & 0.191 \\
\hline Linoleic acid $(\mathrm{C} 18: 2 \mathrm{n}-6 \mathrm{cis})$ & $0.75 \pm 0.03^{\mathrm{a}}$ & $0.74 \pm 0.03^{\mathrm{a}}$ & $1.48 \pm 0.10^{\mathrm{b}}$ & $<0.0005$ \\
\hline Linolelaidic acid (C18:2n-6 trans) & $0.37 \pm 0.17^{\mathrm{a}}$ & $0.58 \pm 0.11^{\mathrm{a}}$ & $0.10 \pm 0.02^{\mathrm{b}}$ & $<0.0005$ \\
\hline$\alpha$-Linolenic acid (C18:3n-3) & $0.67 \pm 0.05^{\mathrm{a}}$ & $0.67 \pm 0.05^{\mathrm{a}}$ & $0.32 \pm 0.03^{\mathrm{b}}$ & $<0.0005$ \\
\hline Arachidic acid (C20:0) & $0.12 \pm 0.01^{\mathrm{a}}$ & $0.13 \pm 0.02^{\mathrm{a}}$ & $0.15 \pm 0.01^{\mathrm{b}}$ & 0.003 \\
\hline Gondoic acid (C20:1) & $0.10 \pm 0.04^{\mathrm{a}}$ & $0.11 \pm 0.06^{\mathrm{a}}$ & $0.06 \pm 0.01^{\mathrm{a}}$ & 0.095 \\
\hline Eicosadienoic acid (C20:2) & $0.00 \pm 0.00^{\mathrm{a}}$ & $0.00 \pm 0.00^{\mathrm{a}}$ & $0.03 \pm 0.02^{\mathrm{b}}$ & $<0.0005$ \\
\hline Eicosatrienoic acid (C20:3n-6) & $0.06 \pm 0.02^{\mathrm{a}}$ & $0.08 \pm 0.04^{\mathrm{a}}$ & $0.08 \pm 0.01^{\mathrm{a}}$ & 0.310 \\
\hline Eicosapentaenoic acid (C20:5) & $0.08 \pm 0.02^{\mathrm{a}}$ & $0.08 \pm 0.02^{\mathrm{a}}$ & $0.03 \pm 0.02^{\mathrm{b}}$ & 0.001 \\
\hline Heneicosylic acid (C21:0) & $0.06 \pm 0.01^{\mathrm{ab}}$ & $0.08 \pm 0.02^{\mathrm{b}}$ & $0.06 \pm 0.01^{\mathrm{a}}$ & 0.021 \\
\hline Behenic acid $(\mathrm{C} 22: 0)$ & $0.06 \pm 0.01^{\mathrm{a}}$ & $0.08 \pm 0.01^{\mathrm{b}}$ & $0.07 \pm 0.01^{\mathrm{ab}}$ & 0.004 \\
\hline Lignoceric acid (C24:0) & $0.32 \pm 0.15^{\mathrm{a}}$ & $0.40 \pm 0.19^{\mathrm{a}}$ & $0.24 \pm 0.29^{\mathrm{a}}$ & 0.489 \\
\hline CLA (cis-9,trans-11) & $1.55 \pm 0.06^{\mathrm{a}}$ & $1.81 \pm 0.28^{\mathrm{a}}$ & $0.45 \pm 0.05^{\mathrm{b}}$ & $<0.0005$ \\
\hline SFA & $76.52 \pm 0.27^{\mathrm{a}}$ & $75.37 \pm 2.51^{\mathrm{a}}$ & $79.48 \pm 1.10^{\mathrm{b}}$ & 0.001 \\
\hline UFA & $23.48 \pm 0.27^{\mathrm{a}}$ & $24.50 \pm 2.42^{\mathrm{a}}$ & $20.45 \pm 1.11^{\mathrm{b}}$ & 0.001 \\
\hline MUFA & $20.00 \pm 0.30^{\mathrm{a}}$ & $20.54 \pm 2.12^{\mathrm{ab}}$ & $17.96 \pm 0.99^{\mathrm{b}}$ & 0.012 \\
\hline PUFA & $3.49 \pm 0.22^{\mathrm{a}}$ & $3.96 \pm 0.31^{\mathrm{b}}$ & $2.49 \pm 0.13^{\mathrm{c}}$ & $<0.0005$ \\
\hline $\mathrm{n}-3$ & $0.67 \pm 0.05^{\mathrm{a}}$ & $0.67 \pm 0.05^{\mathrm{a}}$ & $0.32 \pm 0.03^{\mathrm{b}}$ & $<0.0005$ \\
\hline $\mathrm{n}-6$ & $1.18 \pm 0.16^{\mathrm{a}}$ & $1.39 \pm 0.14^{\mathrm{ab}}$ & $1.66 \pm 0.08^{\mathrm{b}}$ & $<0.0005$ \\
\hline n-9 & $17.35 \pm 0.38^{\mathrm{a}}$ & $17.83 \pm 1.91^{\mathrm{ab}}$ & $15.53 \pm 1.01^{\mathrm{b}}$ & 0.016 \\
\hline $\mathrm{n}-3+\mathrm{CLA}$ & $2.22 \pm 0.05^{\mathrm{a}}$ & $2.49 \pm 0.33^{\mathrm{a}}$ & $0.77 \pm 0.08^{\mathrm{b}}$ & $<0.0005$ \\
\hline$n-3: n-6$ & $0.57 \pm 0.05^{\mathrm{a}}$ & $0.49 \pm 0.07^{\mathrm{b}}$ & $0.19 \pm 0.02^{\mathrm{c}}$ & $<0.0005$ \\
\hline $\mathrm{n}-6:(\mathrm{n}-3+\mathrm{CLA})$ & $0.53 \pm 0.06^{\mathrm{a}}$ & $0.57 \pm 0.11^{\mathrm{a}}$ & $2.19 \pm 0.22^{\mathrm{b}}$ & $<0.0005$ \\
\hline Atherogenicity index & $4.00 \pm 0.09^{\mathrm{a}}$ & $3.92 \pm 0.53^{\mathrm{a}}$ & $4.70 \pm 0.32^{\mathrm{b}}$ & 0.003 \\
\hline Thrombogenic index & $4.06 \pm 0.03^{\mathrm{a}}$ & $3.97 \pm 0.42^{\mathrm{a}}$ & $5.32 \pm 0.37^{\mathrm{b}}$ & $<0.0005$ \\
\hline Spreadability index (C16:0/C18:1) & $1.77 \pm 0.10^{\mathrm{a}}$ & $1.70 \pm 0.20^{\mathrm{a}}$ & $2.28 \pm 0.20^{\mathrm{b}}$ & $<0.0005$ \\
\hline $\mathrm{L}^{*}$ & $81.5 \pm 4.9^{\mathrm{a}}$ & $83.1 \pm 2.4^{\mathrm{a}}$ & $85.6 \pm 1.9^{\mathrm{b}}$ & 0.006 \\
\hline$a^{*}$ & $-3.9 \pm 0.2^{\mathrm{a}}$ & $-4.0 \pm 0.3^{\mathrm{a}}$ & $-4.3 \pm 0.2^{\mathrm{b}}$ & 0.001 \\
\hline$b^{*}$ & $32.5 \pm 1.5^{\mathrm{a}}$ & $32.2 \pm 1.0^{\mathrm{a}}$ & $26.3 \pm 1.1^{\mathrm{b}}$ & $<0.0005$ \\
\hline
\end{tabular}

${ }^{a-c}$ Different superscripts within the same row indicate significant differences among the samples at $P<0.05$.

${ }^{1} \mathrm{GRS}=$ perennial ryegrass; CLV $=$ perennial ryegrass and white clover.

spreadability indices [calculated as the ratio of $\mathrm{C} 16: 0$ to C18:1 (O'Callaghan et al., 2016a)], also consistent with previous studies (Couvreur et al., 2006; O'Callaghan et al., 2016a).

In terms of individual FA, some of the differences recently reported by O'Callaghan et al. (2016a) were confirmed in the present study, such as lower CLA, pentadecanoic, linolelaidic, and $\alpha$-linolenic acid, and higher linoleic and palmitic acid contents in TMR butter compared with the pasture-derived samples. However, the depletion of behenic acid in pasture-derived butter previously reported by O'Callaghan et al. (2016a) was not observed in this study. Similarly, significantly reduced percentages of pentadecanoic and heptadecanoic acids, and increased amounts of palmitic and arachidic acids, were observed in TMR butter compared with pasture-based butter, which was consistent with work by Couvreur et al. (2006).

Fewer differences in FA composition were observed between the 2 pasture-based feeding systems (GRS and CLV). The GRS butter had significantly higher butyric acid contents, whereas myristoleic acid was significantly higher in CLV butter. However, some of the differences observed between GRS and TMR butters were not sta- 
tistically significant for CLV (e.g., oleic acid, tridecanoic acid, undecanoic acid), due to a greater dispersion of the data for those FA.

To assess whether the observed differences in FA composition were enough to clearly discriminate the samples according to their feeding system, multivariate analyses were carried out. Both PCA and PLS-DA were conducted, and results are shown in Figure 1. As expected, PLS-DA yielded a greater extent of separation between the 3 different diets than PCA, because the former is considered a supervised method for dimensionality reduction (i.e., it takes into account the class labels or groups to which each sample belongs for the transformation of the variables; Perez and Narasimhan, 2018). The 3 different diets could be clearly distinguished by PLS-DA based on their FA profile (Figure 1A), which is consistent with previous work (O'Callaghan et al., 2016a). However, due to the small sample set used in this study, supervised methods such as PLS-DA may have limitations, as denoted by the permutation test yielding a $P$-value $>0.05$. The FA that had the greatest effect on this separation were linoleic acid, linolelaidic acid, $\alpha$-linolenic acid, CLA, and pentadecanoic acid (Figure 1B), which were all significantly different between TMR and the pasture-based diets but not between GRS and CLV (Table 1). Indeed, the unsupervised PCA analysis, which was considered more appropriate for the reduced data set available, was not able to differentiate between the pasture-based diets based on their FA composition (Figure 1C), as was to be expected given the similarities between the pasture diets. Nevertheless, butter derived from TMR could be clearly distinguished from pasture-based butter using the unsupervised PCA method. Some of these differences could also be observed in the hierarchical clustering analysis (heatmap) shown in Figure 1D.

\section{Color Analysis}

The yellow coloration of dairy products has been related to their $\beta$-carotene content (O'Callaghan et al., 2016a). Carotenoids, and in particular $\beta$-carotene, have long been attributed to several health benefits when consumed in sufficient quantities (Rock, 1997; Maiani et al., 2009). Therefore, the content of carotenoids in dairy products can be considered another relevant indicator of their nutritional quality. The color coordinates (CIE $\mathrm{L}^{*} \mathrm{a}^{*} \mathrm{~b}^{*}$ ) of the different types of butter are shown in Table 1 , where $\mathrm{L}^{*}, \mathrm{a}^{*}$, and $\mathrm{b}^{*}$ define their position on the dark-light axis, the green-red axis, and the blue-yellow axis, respectively (Nozière et al., 2006). These were significantly different for TMR compared with pasture-based butter, although, again, no significant differences were observed between the 2 different pasture-based diets. The greater $\mathrm{L}^{*}$ values obtained for TMR butter indicate that these were somewhat whiter, whereas the higher $\mathrm{a}^{*}$ and $\mathrm{b}^{*}$ values obtained for GRS and CLV samples imply these were more red and yellow. Indeed, higher $\mathrm{b}^{*}$ values have been directly correlated with greater trans- $\beta$-carotene contents in pasture-derived butter (O'Callaghan et al., 2016a), which suggests that GRS and CLV butter had higher contents of carotenoids, as previously reported.

\section{Raman Spectroscopy Analysis of Butter}

Figure 2 shows the normalized, average spectra of the 9 butter samples. Their most relevant bands are identified in Table 2, based on previous works (SadeghiJorabchi et al., 1990; Baeten et al., 1998; Beattie et al., 2004b; Meurens et al., 2005; McGoverin et al., 2009; Gallier et al., 2011; Czamara et al., 2015). Clear differences could be observed between the spectra of discrete feeding systems. For instance, the intensity of the bands centered around 1,012, 1,162, and 1,525 rel. $\mathrm{cm}^{-1}$, all attributed to the presence of carotenoids (Gallier et al., 2011), and the band centered at 1,659 rel. $\mathrm{cm}^{-1}$, ascribed to the stretching vibration of $\mathrm{C}=\mathrm{C}$ bonds (Czamara et al., 2015), was considerably lower for the TMR samples (see arrows in Figure 2). This was consistent with the lower concentration of carotenoids and SFA, as suggested by the color and fatty acid analysis previously discussed, relative to butter from TMR diets (Table 1). The unsaturation level of fats can be estimated from their Raman spectra by calculating the ratio of intensities of their bands at 1,659 and $1,445 \mathrm{~cm}^{-1}$ (Gallier et al., 2011). According to this ratio (I1659/I1445), the unsaturation levels of CLV, GRS, and TMR butter samples were $0.47 \pm 0.05,0.44 \pm 0.02$, and $0.29 \pm 0.03( \pm \mathrm{SD})$, respectively. Accordingly, the degree of unsaturation was estimated to be about 1.5 times higher for pasture-based butter than for TMR butter.

To assess the potential of the Raman spectral data to discriminate butter samples according to the feeding system from which they had been produced, multivariate analyses were carried out, the results of which are presented in Figure 3. Again, although the 3 different diets could be clearly distinguished by PLS-DA based on their Raman spectra (Figure 3A), the supervised method as applied has limitations relative to reduced data sets. Unsupervised PCA analysis, considered more appropriate, was unable to discriminate between the pasture-based diets (Figure 3C). Notwithstanding, TMR butter could be clearly distinguished from pasture-based butter using Raman spectroscopy coupled with PCA analysis. Interestingly, the heatmap obtained through hierarchical clustering analysis of the spectra 
A)

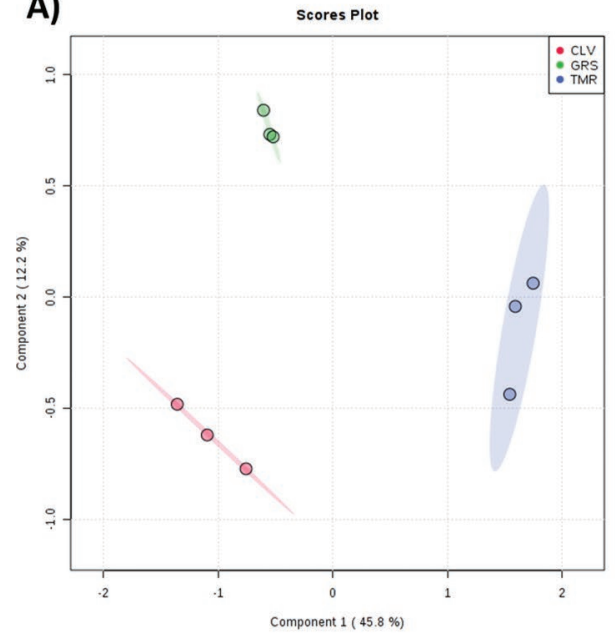

B)

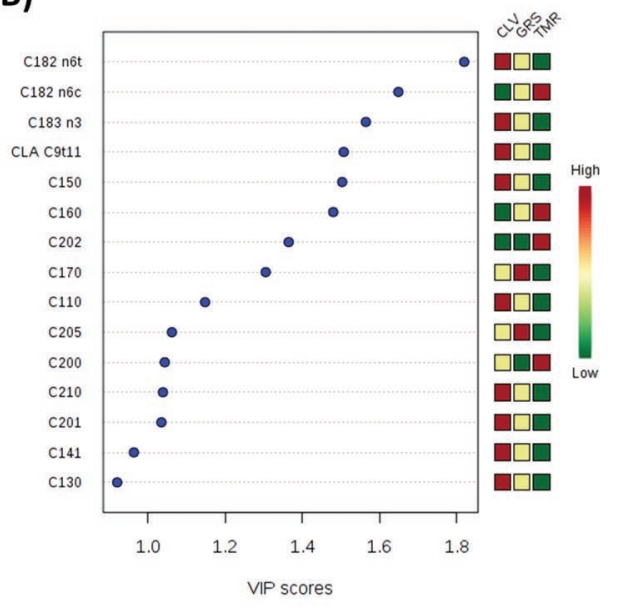

C)

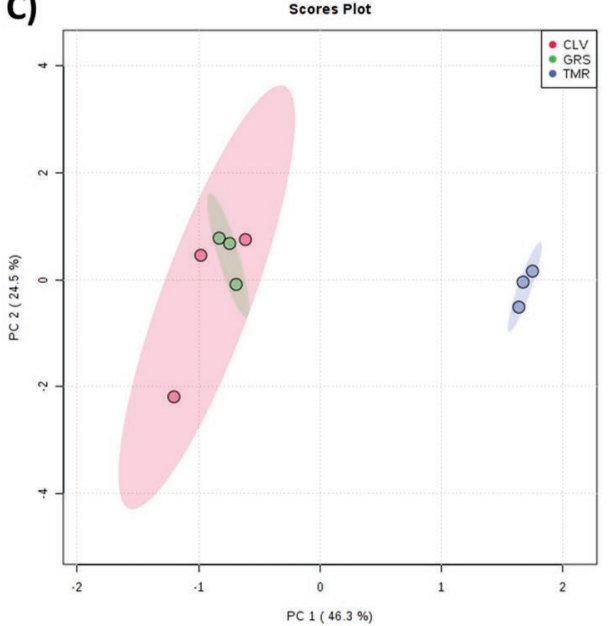

D)

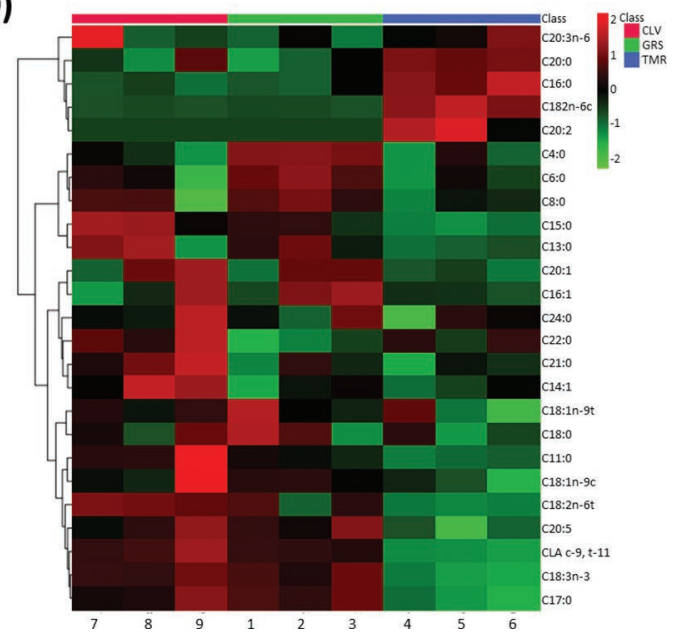

Figure 1. Scores plot and variable importance in projection (VIP) scores from partial least squares discriminant analysis (A, B); scores plot from principal component (PC) analysis (C); and hierarchical clustering analysis (D) used to group the assayed butter samples based on their fatty acid profile, according to cow feeding system. CLV = perennial ryegrass with white clover pasture; GRS = perennial ryegrass pasture; $t$ $=$ trans; $\mathrm{c}=$ cis

(Figure 3D) revealed a much clearer differentiation between the TMR and pasture-based diets than that obtained from the FA analysis (Figure 1D).

According to the variable importance in projection (VIP) scores, the 10 Raman spectral bins with the greatest importance in terms of distinguishing between the 3 diets were in the range of 1,674 to $1,640 \mathrm{rel} . \mathrm{cm}^{-1}$ (ascribed to stretching of $\mathrm{C}=\mathrm{C}$ bonds), 2,892 to 2,807 rel. $\mathrm{cm}^{-1}$ (corresponding to stretching of $-\mathrm{CH}_{2}$ and $-\mathrm{CH}_{3}$ groups), and 3,001 to 3,003 rel. $\mathrm{cm}^{-1}$ and 1,268 rel. $\mathrm{cm}^{-1}$ (due to asymmetric stretching and deformation of $=\mathrm{CH}$ groups, respectively; Czamara et al., 2015). These are mainly related to the degree of unsaturation of the samples. Indeed, significant differences in the content of UFA were identified in Table 1. Other relevant spectral bins include those at 1,191 rel. $\mathrm{cm}^{-1}$ (ascribed to vibrations of the $\mathrm{C}-\mathrm{C}$ backbone), 1,010 rel. $\mathrm{cm}^{-1}$ (stretching of $\mathrm{C}-\mathrm{C}$ bonds), and 1,150 rel. $\mathrm{cm}^{-1}$ (ascribed to the presence of carotenoids and stretching of $\mathrm{C}-\mathrm{C}$ bonds; Figure 3D). To better understand the correlations between the Raman spectra of the samples and their nutritional quality, correlation analyses were also performed, and the results are summarized in the next section.

\section{Correlation Between Raman Spectra and Composition}

A Pearson correlation analysis was carried out to investigate the correlations between the Raman spectra of the butter samples and their color and fatty acid composition. Supplemental Table S1 (https://doi.org/ 


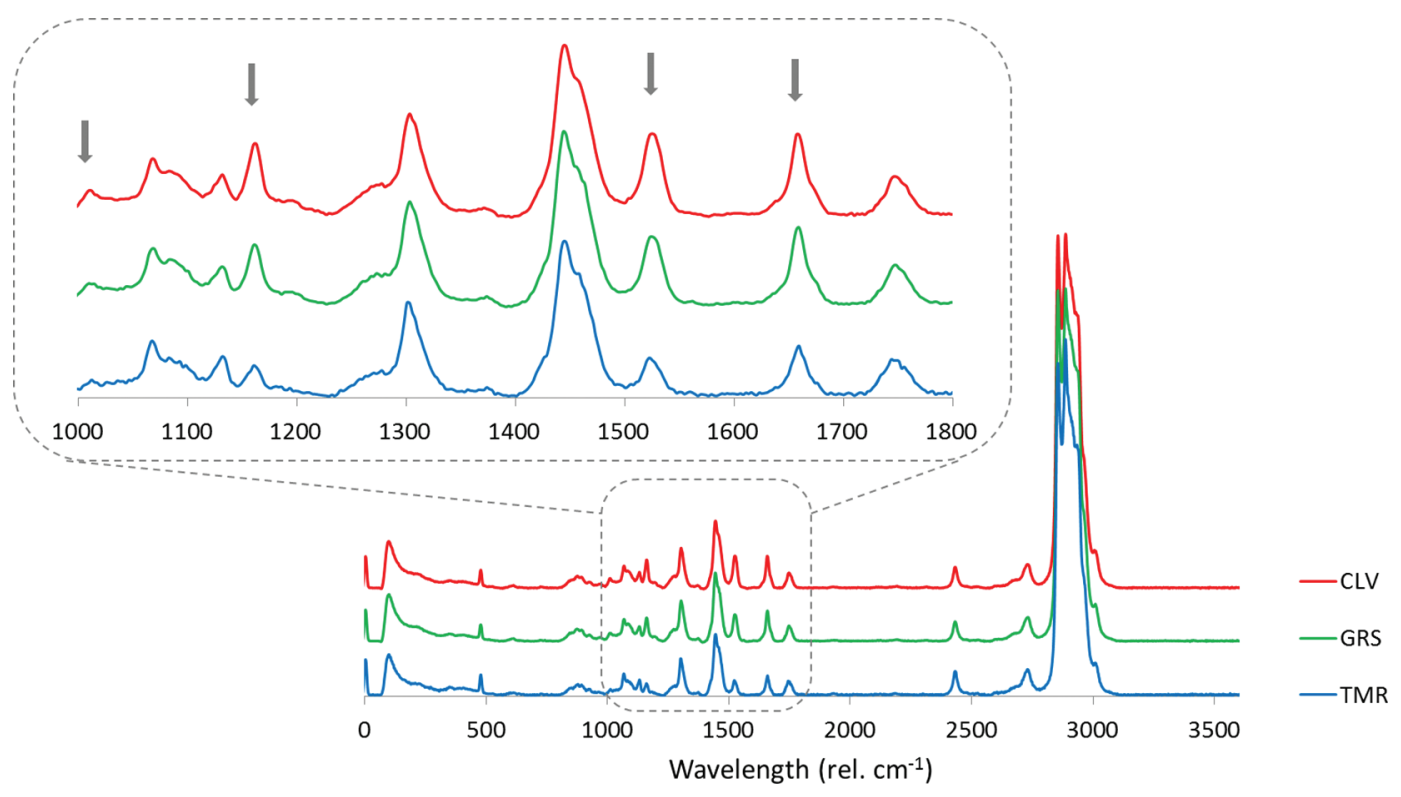

Figure 2. Normalized average Raman spectra of the butter samples for each diet group. CLV = perennial ryegrass with white clover pasture; GRS = perennial ryegrass pasture. Arrows indicate bands that exhibit clear visual differences between diets.

10.3168/jds.2020-18716) shows the correlation matrix (Pearson r-values). The highest positive correlations $(\mathrm{r}>0.98)$ were found between the concentrations of $\alpha$-linolenic acid and CLA and the spectral bin at 1,657

Table 2. Assignments of main Raman bands from butter ${ }^{1}$

\begin{tabular}{|c|c|c|c|}
\hline \multicolumn{3}{|c|}{ Average peak maximum ${ }^{2}$ (rel. $\left.\mathrm{cm}^{-1}\right)$} & \multirow[b]{2}{*}{ Identification $^{3}$} \\
\hline TMR & GRS & CLV & \\
\hline 3,006 & 3,006 & 3,006 & $\nu_{\mathrm{as}}(=\mathrm{CH})$ \\
\hline 2,887 & 2,887 & 2,887 & $\nu_{\mathrm{s}}\left(-\mathrm{CH}_{3}\right) / \nu_{\mathrm{as}}\left(-\mathrm{CH}_{2}\right)$ \\
\hline 2,855 & 2,856 & 2,856 & $\nu_{\mathrm{s}}\left(-\mathrm{CH}_{2}\right)$ \\
\hline 2,730 & 2,730 & 2,730 & \\
\hline 2,606 & - & 2,597 & \\
\hline 2,432 & 2,432 & 2,432 & \\
\hline 1,746 & 1,748 & 1,748 & $\nu(\mathrm{C}=\mathrm{O})$ \\
\hline 1,659 & 1,659 & 1,659 & $\nu(\mathrm{C}=\mathrm{C})$ \\
\hline 1,523 & 1,525 & 1,525 & Carotenoids \\
\hline 1,445 & 1,445 & 1,445 & $\alpha\left(-\mathrm{CH}_{2}\right)$ \\
\hline 1,374 & 1,373 & 1,369 & \\
\hline 1,302 & 1,303 & 1,303 & $\tau\left(-\mathrm{CH}_{2}\right)$ \\
\hline 1,161 & 1,162 & 1,162 & $\nu(\mathrm{C}-\mathrm{C})$, carotenoids \\
\hline 1,132 & 1,130 & 1,130 & $\nu(\mathrm{C}-\mathrm{C})$ \\
\hline 1,068 & 1,068 & 1,069 & $\nu(\mathrm{C}-\mathrm{C})$ \\
\hline 1,015 & 1,012 & 1,012 & Carotenoids \\
\hline - & 968 & 969 & \\
\hline 924 & 925 & 925 & \\
\hline 891 & - & 876 & \\
\hline 877 & 876 & 788 & $\mathrm{C}-\mathrm{O}-\mathrm{O}$ \\
\hline
\end{tabular}

${ }^{1}$ Assignments based on studies by Sadeghi-Jorabchi et al., 1990; Baeten et al., 1998; Beattie et al., 2004b; Meurens et al., 2005; McGoverin et al., 2009; Gallier et al., 2011; and Czamara et al., 2015.

${ }^{2} \mathrm{GRS}=$ perennial ryegrass diet; $\mathrm{CLV}=$ perennial ryegrass and white clover diet.

${ }^{3} \nu=$ stretching $(\mathrm{s}=$ symmetric, as $=$ asymmetric $) ; \alpha=$ scissoring; $\tau$ = twisting. rel. $\mathrm{cm}^{-1}$, which indeed falls in the region of the Raman spectra ascribed to the stretching vibrations of $\mathrm{C}=\mathrm{C}$ bonds. However, it is worth mentioning that the Raman spectrum of a sample is the result of all the components present in it and their interactions, so correlations with individual compounds must be treated carefully. For instance, a negative correlation was found between that same spectral bin and some other PUFA, such as linoleic acid $(\mathrm{r}<-0.94)$. This could be attributable to the significantly higher concentrations of linoleic acid in the TMR samples than in the pasture-derived samples, despite the higher overall content of PUFA in the latter. This also suggests that it may be more appropriate to conduct a correlation analysis taking into account generalized nutritional properties (e.g., PUFA content) of the butter samples rather than individual FA. A new correlation analysis was thus conducted using the functionality and nutritional indexes calculated from the individual FA content (cf Table 1). Table 3 shows part of the obtained correlation matrix (Pearson r-values), where only the spectral bins and variables showing $|\mathrm{r}|$ $>0.96$ in at least 1 line or column are shown. The full correlation matrix can be found in Supplemental Table S2 (https://doi.org/10.3168/jds.2020-18716).

The highest positive correlations in this case $(\mathrm{r}>$ 0.98 ) were found between the aforementioned spectral bin at 1,657 rel. $\mathrm{cm}^{-1}$ (and others in the same region) and the concentration of n-3 and n-3+CLA FA. This region of the spectra was also positively correlated with the concentration of PUFA in the samples $(\mathrm{r}>0.97)$. The region of the spectra at 1,245 to $1,250 \mathrm{rel} . \mathrm{cm}^{-1}$ 
A)

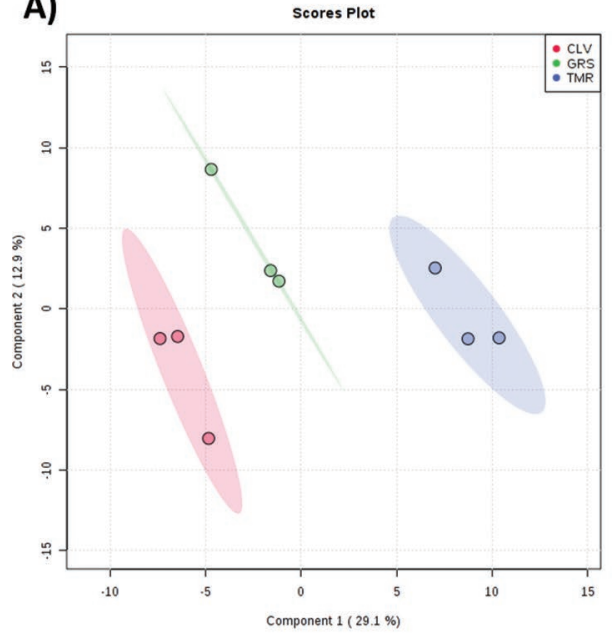

B)

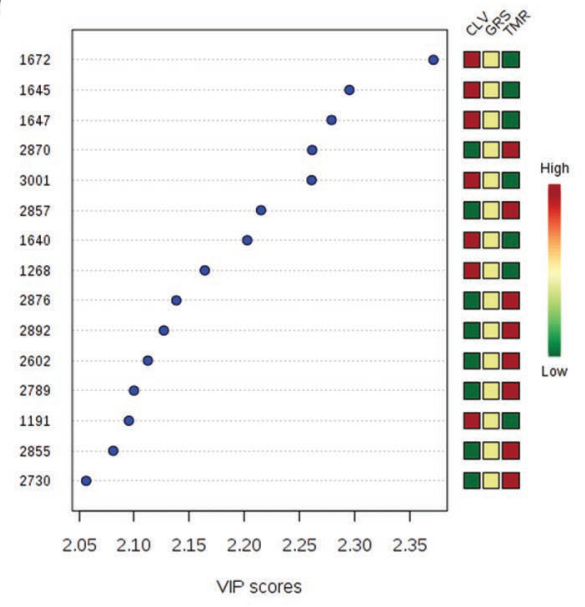

C)

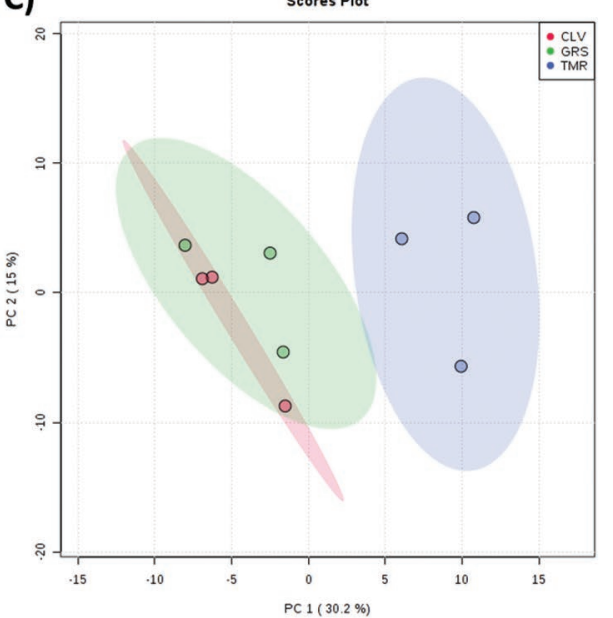

D)

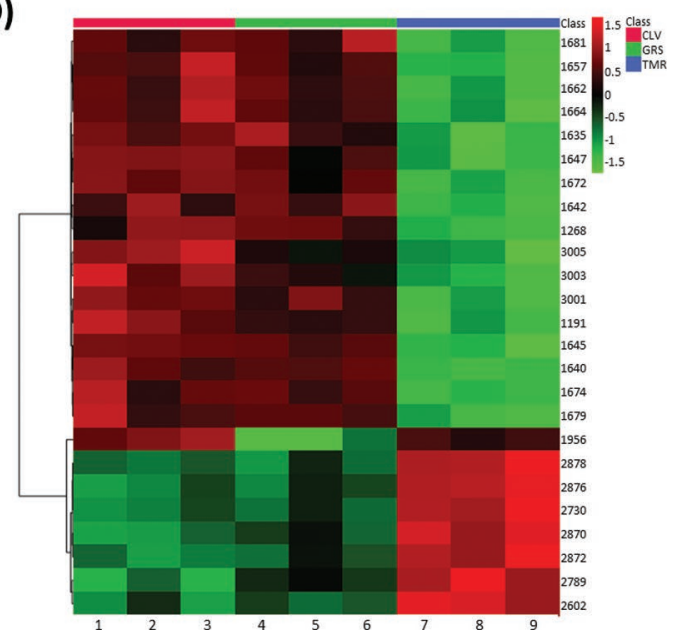

Figure 3. Scores plot and variable importance in projection (VIP) scores from partial least squares discriminant analysis (A, B); scores plot from principal component (PC) analysis (C); and hierarchical clustering analysis (D) used to group the assayed butter samples based on their Raman spectra, according to cow feeding system. CLV = perennial ryegrass with white clover pasture; GRS = perennial ryegrass pasture.

could also be a potential indicator of the presence of PUFA and n-3 or n-3+CLA FA ( $r>0.97)$. The spectral bin at $3,027 \mathrm{rel} . \mathrm{cm}^{-1}$ (and others close to it) was also positively correlated with the presence of n-3 and n$3+$ CLA FA $(\mathrm{r}>0.97)$.

Of the color coordinates, $\mathrm{b}^{*}$ (indicative of the yellow color in butter) was the one with the greatest extent of correlation with the spectra, as expected. However, the peaks at 1,162 and 1,525 rel. $\mathrm{cm}^{-1}$, which have been previously attributed to the presence of carotenoids in butter, did not have the highest positive correlation with $\mathrm{b}^{*}$. On the contrary, the regions around 1,268, 1,652 to 1,659 , and 3,009 to 3,023 rel. $\mathrm{cm}^{-1}$ had greater correlation values $(\mathrm{r}>0.97)$.

Interestingly, a very strong negative correlation was found between the spectral bin at 3,023 rel. $\mathrm{cm}^{-1}$ and the thrombogenic index of the butter samples $(\mathrm{r}<$
$-0.99)$, suggesting that this region could be a good indicator for this health-related factor in butter. Several regions of the spectra were also negatively correlated with the n-6/(n-3 + CLA) index, namely those at 1,268, 1,640 to $1,645,1,679$, and 2,995 to 3,009 rel. $\mathrm{cm}^{-1}$ (r $<-0.97)$. Overall, the Raman spectra of the butter samples showed strong correlations with variables generally recognized as indicators of the nutritional quality of butter.

\section{CONCLUSIONS}

Both FA analysis and the proposed Raman spectroscopy approach could successfully distinguish butter derived from TMR diets from that of pasture-derived butter using PCA analysis, although the 2 different pasture based feeding systems could not be differentiated. 
Table 3. Pearson r-values obtained from correlation analysis of the Raman spectra with the nutritional indexes and color coordinates (CIE $\left.\mathrm{L}^{*} \mathrm{a}^{*} \mathrm{~b}^{*}\right)$ of butter samples; only variables showing $|\mathrm{r}|>0.96$ in at least 1 line or column are shown

\begin{tabular}{|c|c|c|c|c|c|c|c|c|}
\hline Spectral bin & PUFA & $\begin{array}{l}\text { Medium- } \\
\text { chain }\end{array}$ & $\mathrm{n}-3$ & n-3+CLA & $\mathrm{n}-6 /(\mathrm{n}-3+\mathrm{CLA})$ & $\begin{array}{l}\text { Thrombogenic } \\
\text { index }\end{array}$ & $\begin{array}{l}\text { Spreadability } \\
\text { index }\end{array}$ & $\mathrm{b}^{*}$ \\
\hline 1,245 & $0.971^{*}$ & -0.903 & $0.972^{*}$ & 0.966 & -0.935 & -0.967 & -0.928 & 0.962 \\
\hline 1,250 & 0.944 & -0.958 & 0.935 & $0.971^{*}$ & -0.963 & -0.945 & -0.927 & 0.940 \\
\hline 1,268 & 0.899 & -0.927 & 0.955 & 0.952 & $-0.974^{*}$ & -0.926 & -0.884 & $0.971^{*}$ \\
\hline 1,275 & 0.882 & -0.961 & 0.924 & 0.927 & -0.952 & -0.900 & -0.889 & 0.922 \\
\hline 1,635 & 0.892 & -0.925 & 0.958 & 0.940 & -0.966 & -0.899 & -0.866 & 0.954 \\
\hline 1,647 & 0.940 & -0.896 & $0.974^{*}$ & 0.955 & -0.958 & -0.899 & -0.844 & 0.962 \\
\hline 1,652 & 0.968 & -0.925 & $0.980^{* *}$ & $0.983^{* *}$ & -0.956 & -0.969 & -0.929 & $0.974^{*}$ \\
\hline 1,655 & 0.967 & -0.933 & $0.975^{*}$ & $0.981^{* *}$ & -0.949 & -0.960 & -0.920 & 0.962 \\
\hline 1,657 & $0.977^{*}$ & -0.942 & $0.985^{* *}$ & $0.990^{* *}$ & -0.962 & -0.961 & -0.920 & 0.966 \\
\hline 1,659 & 0.964 & -0.932 & $0.983^{* *}$ & $0.978^{*}$ & -0.961 & -0.958 & -0.917 & $0.973^{*}$ \\
\hline 1,662 & 0.962 & -0.955 & $0.978^{*}$ & $0.980^{* *}$ & -0.960 & -0.952 & -0.915 & 0.954 \\
\hline 1,664 & 0.967 & -0.954 & $0.977^{*}$ & $0.980^{* *}$ & -0.959 & -0.961 & -0.925 & 0.957 \\
\hline 1,681 & 0.845 & -0.841 & 0.960 & 0.899 & -0.929 & -0.886 & -0.807 & 0.949 \\
\hline 2,772 & -0.928 & 0.966 & -0.930 & -0.942 & 0.928 & 0.931 & 0.920 & -0.897 \\
\hline 2,874 & 0.901 & $-0.974^{*}$ & 0.925 & 0.927 & -0.946 & -0.917 & -0.901 & 0.914 \\
\hline 2,895 & 0.914 & -0.968 & 0.911 & 0.923 & -0.935 & -0.925 & -0.922 & 0.909 \\
\hline 2,995 & 0.902 & -0.960 & 0.952 & 0.946 & $-0.975^{*}$ & -0.939 & -0.912 & 0.960 \\
\hline 3,001 & 0.911 & -0.955 & 0.954 & 0.947 & $-0.972^{*}$ & -0.921 & -0.885 & 0.949 \\
\hline 3,009 & 0.883 & -0.936 & 0.948 & 0.943 & $-0.976^{*}$ & -0.965 & -0.935 & $0.974^{*}$ \\
\hline 3,011 & 0.936 & -0.942 & 0.937 & 0.941 & -0.936 & -0.960 & -0.936 & 0.939 \\
\hline 3,015 & 0.945 & -0.941 & 0.962 & $0.973^{*}$ & -0.969 & -0.968 & -0.940 & $0.974^{*}$ \\
\hline 3,019 & 0.952 & -0.929 & 0.954 & 0.953 & -0.929 & $-0.983^{* *}$ & -0.957 & 0.948 \\
\hline 3,021 & 0.910 & -0.889 & 0.945 & 0.922 & -0.921 & $-0.973^{*}$ & -0.942 & 0.945 \\
\hline 3,023 & 0.934 & -0.944 & 0.967 & $0.972^{*}$ & -0.969 & $-0.994^{* *}$ & -0.966 & $0.975^{*}$ \\
\hline 3,027 & 0.957 & -0.937 & $0.977^{*}$ & $0.980^{* *}$ & -0.963 & $-0.977^{*}$ & -0.933 & 0.969 \\
\hline
\end{tabular}

$*|\mathrm{r}|>0.97 ; * *|\mathrm{r}|>0.98$.

The information obtained from the Raman spectra of butter correlated well with their FA profiles and color coordinates. Strong Pearson correlations were found between the Raman spectral bin at $1,657 \mathrm{rel} . \mathrm{cm}^{-1}$ and the concentrations of n-3 and n-3+CLA FA ( $r>0.98)$ and PUFA $(r>0.97)$ in the samples. Additionally, the spectral bin at 3,023 rel. $\mathrm{cm}^{-1}$ was found to be a good indicator to predict the thrombogenic index of butter $(\mathrm{r}<-0.99)$. Overall, this work shows the potential of Raman spectroscopy coupled with multivariate analysis to distinguish butter derived from TMR diets from pasture-derived butter, and to predict factors generally recognized as indicators of the nutritional quality of butter. Further research is anticipated to validate these results on samples obtained varying additional factors besides the diet.

\section{ACKNOWLEDGMENTS}

This project was funded by Teagasc, the Irish Agricultural and Food Development Authority (Fermoy,
Ireland). The authors have not stated any conflicts of interest.

\section{REFERENCES}

Agabriel, C., A. Cornu, C. Journal, C. Sibra, P. Grolier, and B. Martin. 2007. Tanker milk variability according to farm feeding practices: Vitamins A and E, carotenoids, color, and terpenoids. J. Dairy Sci. 90:4884-4896. https://doi.org/10.3168/jds.2007-0171.

Alothman, M., S. A. Hogan, D. Hennessy, P. Dillon, K. N. Kilcawley, M. O'Donovan, J. Tobin, M. A. Fenelon, and T. F. O'Callaghan. 2019. The "grass-fed" milk story: Understanding the impact of pasture feeding on the composition and quality of bovine milk. Foods 8:350. https://doi.org/10.3390/foods8080350.

Baeten, V. 2010. Raman spectroscopy in lipid analysis. Lipid Technol. 22:36-38. https://doi.org/10.1002/lite.200900082.

Baeten, V., P. Hourant, M. T. Morales, and R. Aparicio. 1998. Oil and fat classification by FT-Raman spectroscopy. J. Agric. Food Chem. 46:2638-2646. https://doi.org/10.1021/jf9707851.

Beattie, J. R., S. E. Bell, C. Borgaard, A. Fearon, and B. W. Moss. 2004a. Multivariate prediction of clarified butter composition using Raman spectroscopy. Lipids 39:897-906. https://doi.org/10 $.1007 / \mathrm{s} 11745-004-1312-5$.

Beattie, J. R., S. E. J. Bell, and B. W. Moss. 2004b. A critical evaluation of Raman spectroscopy for the analysis of lipids: Fatty acid methyl esters. Lipids 39:407-419. https://doi.org/10.1007/s11745 -004-1245-z. 
Benbrook, C. M., D. R. Davis, B. J. Heins, M. A. Latif, C. Leifert, L. Peterman, G. Butler, O. Faergeman, S. Abel-Caines, and M. Baranski. 2018. Enhancing the fatty acid profile of milk through forage-based rations, with nutrition modeling of diet outcomes. Food Sci. Nutr. 6:681-700. https://doi.org/10.1002/fsn3.610.

Butler, H. J., L. Ashton, B. Bird, G. Cinque, K. Curtis, J. Dorney, K. Esmonde-White, N. J. Fullwood, B. Gardner, P. L. Martin-Hirsch, M. J. Walsh, M. R. McAinsh, N. Stone, and F. L. Martin. 2016. Using Raman spectroscopy to characterize biological materials. Nat. Protoc. 11:664-687. https://doi.org/10.1038/nprot.2016.036.

Capuano, E., G. van der Veer, R. Boerrigter-Eenling, A. Elgersma, J. Rademaker, A. Sterian, and S. M. van Ruth. 2014. Verification of fresh grass feeding, pasture grazing and organic farming by cows farm milk fatty acid profile. Food Chem. 164:234-241. https://doi .org/10.1016/j.foodchem.2014.05.011.

Chilliard, Y., A. Ferlay, and M. Doreau. 2001. Effect of different types of forages, animal fat or marine oils in cow's diet on milk fat secretion and composition, especially conjugated linoleic acid (CLA) and polyunsaturated fatty acids. Livest. Prod. Sci. 70:31-48. https: //doi.org/10.1016/S0301-6226(01)00196-8.

Chilliard, Y., F. Glasser, A. Ferlay, L. Bernard, J. Rouel, and M. Doreau. 2007. Diet, rumen biohydrogenation and nutritional quality of cow and goat milk fat. Eur. J. Lipid Sci. Technol. 109:828855. https://doi.org/10.1002/ejlt.200700080.

Chong, J., D. S. Wishart, and J. Xia. 2019. Using MetaboAnalyst 4.0 for comprehensive and integrative metabolomics data analysis. Curr. Protoc. Bioinformatics 68:e86. https://doi.org/10.1002/cpbi .86 .

Couvreur, S., C. Hurtaud, C. Lopez, L. Delaby, and J.-L. Peyraud. 2006. The linear relationship between the proportion of fresh grass in the cow diet, milk fatty acid composition, and butter properties. J. Dairy Sci. 89:1956-1969. https://doi.org/10.3168/jds.S0022 -0302(06)72263-9.

Czamara, K., K. Majzner, M. Z. Pacia, K. Kochan, A. Kaczor, and M. Baranska. 2015. Raman spectroscopy of lipids: A review. J. Raman Spectrosc. 46:4-20. https://doi.org/10.1002/jrs.4607.

Dewhurst, R. J., K. Shingfield, M. R. Lee, and N. D. Scollan. 2006. Increasing the concentrations of beneficial polyunsaturated fatty acids in milk produced by dairy cows in high-forage systems. Anim. Feed Sci. Technol. 131:168-206. https://doi.org/10.1016/j .anifeedsci.2006.04.016.

Dong, W., Y. Zhang, B. Zhang, and X. Wang. 2013. Rapid prediction of fatty acid composition of vegetable oil by Raman spectroscopy coupled with least squares support vector machines. J. Raman Spectrosc. 44:1739-1745. https://doi.org/10.1002/jrs.4386.

El-Abassy, R. M., P. J. Eravuchira, P. Donfack, B. Von Der Kammer, and A. Materny. 2012. Direct determination of unsaturation level of milk fat using Raman spectroscopy. Appl. Spectrosc. 66:538 544. https://doi.org/10.1366/11-06327.

Faulkner, H., T. F. O'Callaghan, S. McAuliffe, D. Hennessy, C. Stanton, M. G. O'Sullivan, J. P. Kerry, and K. N. Kilcawley. 2018. Effect of different forage types on the volatile and sensory properties of bovine milk. J. Dairy Sci. 101:1034-1047. https://doi.org/10 $.3168 / j d s .2017-13141$.

Gallier, S., K. C. Gordon, R. Jiménez-Flores, and D. W. Everett. 2011. Composition of bovine milk fat globules by confocal Raman microscopy. Int. Dairy J. 21:402-412. https://doi.org/10.1016/j .idairyj.2011.01.008.

Hara, R., M. Ishigaki, Y. Kitahama, Y. Ozaki, and T. Genkawa. 2018. Excitation wavelength selection for quantitative analysis of carotenoids in tomatoes using Raman spectroscopy. Food Chem. 258:308-313. https://doi.org/10.1016/j.foodchem.2018.03.089.

Hurtaud, C., L. Delaby, and J.-L. Peyraud. 2007. The nature of preserved forage changes butter organoleptic properties. Lait 87:505519. https://doi.org/10.1051/lait:2007030.

Hurtaud, C., and J. Peyraud. 2007. Effects of feeding camelina (seeds or meal) on milk fatty acid composition and butter spreadability. J. Dairy Sci. 90:5134-5145. https://doi.org/10.3168/jds.2007-0031.

Kučević, D., S. Trivunović, V. Bogdanović, K. Čobanović, D. Janković, and D. Stanojević. 2016. Composition of raw milk from conven- tional and organic dairy farming. Biotechnol. Anim. Husb. 32:133143. https://doi.org/10.2298/BAH1602133K.

Liu, B., P. Zhou, X. Liu, X. Sun, H. Li, and M. Lin. 2013. Detection of pesticides in fruits by surface-enhanced Raman spectroscopy coupled with gold nanostructures. Food Bioprocess Technol. 6:710-718. https://doi.org/10.1007/s11947-011-0774-5.

Magan, J. B., J. T. Tobin, T. F. O'Callaghan, A. L. Kelly, M. A. Fenelon, D. Hennessy, and N. A. McCarthy. 2019. Physicochemical properties of whole milk powder derived from cows fed pasture or total mixed ration diets. J. Dairy Sci. 102:9611-9621. https://doi .org/10.3168/jds.2019-16415.

Maiani, G., M. J. Periago Castón, G. Catasta, E. Toti, I. G. Cambrodón, A. Bysted, F. Granado-Lorencio, B. Olmedilla-Alonso, P. Knuthsen, M. Valoti, V. Böhm, E. Mayer-Miebach, D. Behsnilian, and U. Schlemmer. 2009. Carotenoids: Actual knowledge on food sources, intakes, stability and bioavailability and their protective role in humans. Mol. Nutr. Food Res. 53(Suppl. 2):S194-S218. https://doi.org/10.1002/mnfr.200800053.

Mallia, S., P. Piccinali, B. Rehberger, R. Badertscher, F. Escher, and H. Schlichtherle-Cerny. 2008. Determination of storage stability of butter enriched with unsaturated fatty acids/conjugated linoleic acids (UFA/CLA) using instrumental and sensory methods. Int. Dairy J. 18:983-993. https://doi.org/10.1016/j.idairyj.2008.05 .007 .

McGoverin, C., A. Clark, S. Holroyd, and K. Gordon. 2009. Raman spectroscopic prediction of the solid fat content of New Zealand anhydrous milk fat. Anal. Methods 1:29-38. https://doi.org/10 $.1039 /$ b9ay00111e.

Meurens, M., V. Baeten, S. H. Yan, E. Mignolet, and Y. Larondelle. 2005. Determination of the conjugated linoleic acids in cow's milk fat by Fourier transform Raman spectroscopy. J. Agric. Food Chem. 53:5831-5835. https://doi.org/10.1021/jf0480795.

Nozière, P., B. Graulet, A. Lucas, B. Martin, P. Grolier, and M. Doreau. 2006. Carotenoids for ruminants: From forages to dairy products. Anim. Feed Sci. Technol. 131:418-450. https://doi.org/ 10.1016/j.anifeedsci.2006.06.018.

O'Callaghan, T. F., H. Faulkner, S. McAuliffe, M. G. O'Sullivan, D. Hennessy, P. Dillon, K. N. Kilcawley, C. Stanton, and R. P. Ross. 2016a. Quality characteristics, chemical composition, and sensory properties of butter from cows on pasture versus indoor feeding systems. J. Dairy Sci. 99:9441-9460. https://doi.org/10.3168/jds .2016-11271.

O'Callaghan, T. F., D. Hennessy, S. McAuliffe, K. N. Kilcawley, M. O'Donovan, P. Dillon, R. P. Ross, and C. Stanton. 2016b. Effect of pasture versus indoor feeding systems on raw milk composition and quality over an entire lactation. J. Dairy Sci. 99:9424-9440. https://doi.org/10.3168/jds.2016-10985.

O'Callaghan, T. F., D. T. Mannion, D. Hennessy, S. McAuliffe, M. G. O'Sullivan, N. Leeuwendaal, T. P. Beresford, P. Dillon, K. N Kilcawley, J. J. Sheehan, R. P. Ross, and C. Stanton. 2017. Effect of pasture versus indoor feeding systems on quality characteristics, nutritional composition, and sensory and volatile properties of fullfat Cheddar cheese. J. Dairy Sci. 100:6053-6073. https://doi.org/ 10.3168/jds.2016-12508

O'Callaghan, T. F., M. O'Donovan, J. P. Murphy, K. Sugrue, D. Mannion, W. P. McCarthy, M. Timlin, K. N. Kilcawley, R. M. Hickey, and J. T. Tobin. 2020. Evolution of the bovine milk fatty acid profile-From colostrum to milk five days post parturition. Int. Dairy J. 104:104655.

O'Callaghan, T. F., R. Vázquez-Fresno, A. Serra-Cayuela, E. Dong, R. Mandal, D. Hennessy, S. McAuliffe, P. Dillon, D. S. Wishart, C. Stanton, and R. P. Ross. 2018. Pasture feeding changes the bovine rumen and milk metabolome. Metabolites 8:27. https://doi.org/10 $.3390 /$ metabo8020027.

Olsen, E. F., E.-O. Rukke, A. Flåtten, and T. Isaksson. 2007. Quantitative determination of saturated-, monounsaturated- and polyunsaturated fatty acids in pork adipose tissue with non-destructive Raman spectroscopy. Meat Sci. 76:628-634. https://doi.org/10 .1016/j.meatsci.2007.02.004. 
Peng, Y., M. Liu, X. Chen, H. Yuan, and J. Zhao. 2017. Surfaceenhanced Raman spectroscopy coupled with gold nanoparticles for rapid detection of amoxicillin residues in duck meat. Spectrosc. Lett. 50:579-584. https://doi.org/10.1080/00387010.2017.1397029.

Perez, D. R., and G. Narasimhan. 2018. So you think you can PLSDA? bioRxiv 2018:207225. https://doi.org/10.1101/207225.

Portarena, S., C. Anselmi, C. Zadra, D. Farinelli, F. Famiani, C. Baldacchini, and E. Brugnoli. 2019. Cultivar discrimination, fatty acid profile and carotenoid characterization of monovarietal olive oils by Raman spectroscopy at a single glance. Food Control 96:137-145. https://doi.org/10.1016/j.foodcont.2018.09.011.

Revello Chion, A., E. Tabacco, D. Giaccone, P. G. Peiretti, G. Battelli, and G. Borreani. 2010. Variation of fatty acid and terpene profiles in mountain milk and "Toma piemontese" cheese as affected by diet composition in different seasons. Food Chem. 121:393-399. https://doi.org/10.1016/j.foodchem.2009.12.048.

Rock, C. L. 1997. Carotenoids: Biology and treatment. Pharmacol. Ther. 75:185-197. https://doi.org/10.1016/S0163-7258(97)00054 -5 .
Sadeghi-Jorabchi, H., P. Hendra, R. Wilson, and P. Belton. 1990. Determination of the total unsaturation in oils and margarines by Fourier transform Raman spectroscopy. J. Am. Oil Chem. Soc. 67:483-486. https://doi.org/10.1007/BF02540752.

Ulbricht, T. L., and D. A. Southgate. 1991. Coronary heart disease: Seven dietary factors. Lancet 338:985-992. https://doi.org/10 .1016/0140-6736(91)91846-M

van de Voort, F. R., J. Sedman, and T. Russin. 2001. Lipid analysis by vibrational spectroscopy. Eur. J. Lipid Sci. Technol. 103:815826. https://doi.org/10.1002/1438-9312(200112)103:12<815::AIDE.JLT1111815>3.0.CO;2-P.

White, S. L., J. A. Bertrand, M. R. Wade, S. P. Washburn, J. T. Green Jr., and T. C. Jenkins. 2001. Comparison of fatty acid content of milk from Jersey and Holstein cows consuming pasture or a total mixed ration. J. Dairy Sci. 84:2295-2301. https://doi.org/10.3168/ jds.S0022-0302(01)74676-0. 